\title{
Discriminación infantil de la realidad y ficción en los dibujos animados
}

\section{Children's perception of the reality and fiction in the cartoons}

\author{
$\mathrm{M}^{\mathrm{a}}$ Esther del Moral Pérez \\ Lourdes Villalustre Martínez \\ (Universidad de Oviedo) \\ http://dx.doi.org/10.12795/AdMIRA.2010.01.03
}

\section{Resumen}

Los formatos animados se constituyen en el producto de entretenimiento infantil por excelencia, sin embargo, estos coloristas y atractivos discursos audiovisuales no siempre contemplan guiones y contenidos adecuados para esta audiencia. Los escolares asturianos (Del Moral y Villalustre, 2008) indican que ven series de ficción, aventuras, fantasía, deportivas, de lucha..., otras abordan temáticas familiares realistas o hiperrealistas que caricaturizan las sociedades desarrolladas (Los Simpson, Padre de familia, Shin Chan, etc.). Su "grado de discriminación” sobre las imágenes que perciben es muy precario. A veces se hayan expuestos a relatos que recrean situaciones reales, y otras, totalmente fantásticas propias de un mundo de ficción. La línea divisoria entre la realidad y la ficción se desdibuja, y la percepción limitada de los menores puede llevarles a navegar en la ambigüedad, a generarles inseguridad y/o temor. Pudiendo afectar a su capacidad de análisis, nivel de comprensión e interpretación de la realidad.

Palabras clave: dibujos animados, realidad, ficción, infancia, estereotipos.

\begin{abstract}
The formats are set up in the animated children's entertainment product par excellence, however, these colorful and attractive audiovisual speech scripts and do not always include appropriate content for this audience. The children (Del Moral and Villalustre, 2008) indicate see that series are fiction, adventure, fantasy, sports, action ..., other family-themed realistic or hyper-realistic caricature that developed societies (Simpson, Family Father, Shin Chan, etc.). The degree of discrimination on the images they receive is very precarious. Sometimes they have been exposed to stories that recreate real situations, and other, totally fantastic characteristic of a fictional world. The dividing line between reality and fiction blurs, and the limited perception of children can lead them to navigate ambiguity, to create uncertainty and sometimes fear. His capacity for analysis, understanding and interpretation of some of the messages that are distilled through the animated series they see, not always conform to the intent and subtle criticism of the creators of these stories. It can affect their capacity for analysis, understanding and interpretation of reality.
\end{abstract}

Keywords: cartoons, reality, fiction, children, stereotypes.

\section{Introducción}


La televisión ofrece al público infantil y juvenil una programación basada en un discurso ágil, recurrente y sin trasfondo reflexivo, que puede lograr manipular la percepción de la realidad de estos espectadores, especialmente vulnerables por hallarse en pleno desarrollo madurativo.

No se puede perder de vista que los dibujos animados son unos peculiares formatos en los que se cuentan historias a través de unos muñecos que toman vida ubicados en escenarios coloristas, y que aderezados con todo tipo de recursos expresivos son dotados de gran atractivo, especialmente para el público infantil (Del Moral, 2004). Su visionado constituye una práctica de entretenimiento muy frecuente a partir de la cual, y desde el punto de vista psicológico, los niños/as, por ósmosis van construyendo la realidad, incluida la realidad social.

El aprendizaje humano se lleva a cabo en los primeros años de la infancia a través de la imitación (Bandura, 1983), los más pequeños repican tanto los modelos parentales observados, como los del grupo de iguales, y los de los personajes televisivos contemplados. El poder de ascendencia de éstos va en proporción directa con el tiempo de exposición y con su implicación afectiva con cada uno de ellos, y teniendo presente que hoy los menores permanecen un gran número de horas frente a las pantallas, para algunos es preocupante que sus únicos referentes sean los protagonistas de sus series favoritas, y, por ende, sus principales "educadores". Cuyas conductas pueden ser aprendidas y reproducidas como válidas de forma acrítica, con el riesgo de que no se ajusten a los parámetros éticos y culturales de una sociedad que dice velar por subrayar los valores democráticos y los derechos de igualdad y respeto de todos los ciudadanos (Del Moral, 2010).

La temática de los relatos y los personajes que se representan en los dibujos animados actúan como intermediarios en la formación intelectual y conductual de los menores. Y sucede que, a menudo la presentación de determinadas situaciones y comportamientos proporcionan una simplificación de una realidad compleja en la que la discriminación entre realidad y ficción no siempre se establece de forma explícita, lo que puede llegar a confundir y a afectar al desarrollo cognitivo del niño/a. 
Las series animadas, que con frecuencia son vistas por los más pequeños, están protagonizadas de numerosos personajes con poderes mágicos, con una capacidad insólita para vivir situaciones violentas de las que salen ilesos, etc. Sin embargo, el niño en las primeras etapas de su vida entiende lo representado en la pantalla de forma literal, sin establecer una distinción entre realidad y ficción, ya que, según Piaget (1933) su pensamiento se caracteriza por la desconexión con la realidad y la ausencia de lógica, apoyándose éste en la imaginación y la ficción.

La implicación emocional de los/as niños/as en las historias ficticias y animadas ocasiona una gran dificultad para su discriminación con la realidad, al provocar en ellos fuertes reacciones emocionales y sumergirles en el mundo de ficción como si éste fuera real. Por tanto, tal y como establece Giménez (2003), la ficción posee elementos capaces de inducir reacciones emocionales intensas.

Han sido numerosas las investigaciones (Harris y otros, 1991; Woolley y Phelps, 1994; Taylor, 1999; Subbostky, 2000; entre otros) que han tenido como objetivo delimitar los límites en los cuales los niños son capaces de establecer una línea divisoria entre la ficción y la realidad. De sus resultados se puede desprender que el pensamiento infantil tiende a confundir la realidad y la ficción cuando no disponen de una argumentación racional que explique las situaciones confusas que perciben. De este modo, cuando en una serie de dibujos animados los personajes sobreviven a situaciones de peligro extremo sin sufrir ningún daño, el niño recurre a un razonamiento causal mágico para explicarlo, llegando a imponerse y a orientar su conducta.

En este sentido, los dibujos animados emitidos en horarios infantiles deberían someterse a un proceso de evaluación antes de emitirse, con objeto de controlar los efectos cognitivos, afectivos y conductuales poco deseables que puedan afectar sobre todo al público infantil y juvenil, ya que éstos son los más vulnerables al carecer de un juicio crítico formado, y por hallarse en pleno desarrollo psicológico y madurativo, y tienen dificultad para definir los límites entre el mundo real y ficticio de forma estricta.

Tal y como hemos apuntado anteriormente, el niño y la niña aprenden en sus primeros años, a través de la imitación. Imitan las actuaciones y actitudes de su entorno (padres, hermanos, amigos, ...) y de los personajes que observan en el televisor, copiando lo que hacen o dicen, e ignorando la diferencia entre lo real y lo ficticio. Asimismo, 
interiorizan estereotipos a través de los rasgos asociados a los personajes de ficción que consumen con mayor frecuencia.

Por otro lado, las reacciones de miedo o de inseguridades de los más pequeños, manifestadas a través de las pesadillas y temores nocturnos, se encuentran estrechamente relacionadas con el tipo de contenidos televisivos a los que han estado expuestos. Gordo (1999) realizó un estudio en el que analizaba la influencia de la televisión en los sueños traumáticos de los menores, afirmando que los contenidos de las series de ficción protagonizadas por figuras terroríficas poseen un gran influjo y repercusión en los sueños infantiles. Generando un alto nivel de angustia como consecuencia de la dificultad que los más pequeños encuentran para comprender determinados contenidos adultos integrados en los relatos infantiles, o por hallarse en programaciones emitidas en horarios protegidos supuestamente dirigidos a la infancia.

Teniendo en cuenta lo expuesto, consideramos necesario efectuar un análisis más en profundidad de los contenidos transmitidos por la televisión, y más específicamente por las series animadas, que lleve a cuestionarnos por la pertinencia o no de los modelos presentados a los menores.

Se ha realizado un estudio para determinar el grado de discriminación entre realidad y ficción que perciben los menores asturianos a través de los dibujos animados que habitualmente consumen, y cuyos resultados se presentan a continuación.

\section{Grado de discriminación entre realidad y ficción de los escolares asturianos}

\section{Contexto y muestra estudio consultada}

Los datos que se presentan proceden de una investigación más amplia, titulada: $L a$ mediación de las pantallas: televisión y videojuegos, controvertidos modelos para el aprendizaje cognitivo-social, financiada por la Universidad de Oviedo (2008). Donde se recogen las opiniones de los escolares de Educación Primaria del Principado de Asturias, acerca de su consideración sobre si las aventuras animadas que ven, pueden darse en la realidad, para analizar entre las respuestas afirmativas las diferentes justificaciones que efectúan al respecto. 
La muestra de estudio constaba de 533 niños y niñas pertenecientes a tercero, cuarto y quinto curso de Primaria en ocho colegios de diferentes zonas de Asturias (Oviedo, Gijón, Mieres y Laviana) elegidos al azar, de los cuales un aproximado 53 \% de ellos eran niños y un 47 \% niñas. Donde algo más del 67\% de los encuestados tenían edades comprendidas entre los 7 y 10 años, y un casi 30\%, 8 años o menos.

\section{Información recabada}

El cuestionario pretendía recopilar datos sobre el consumo televisivo de los menores en general, que incluía entre otros aspectos, la enumeración que los menores hacían del tipo de situaciones mostradas en los dibujos animados que habitualmente visionan y consideran que pueden darse en la realidad.

A continuación, y con objeto de contextualizar el análisis que nos ocupa, se han extraído, algunos datos de interés que contribuyen a explicar en gran parte las justificaciones de los menores en cuanto al tipo de situaciones de ficción que pueden producirse en un contexto real. Así, se obtuvo información sobre:

a) El tipo de programa televisivo que los menores dicen visionar en mayor medida en su tiempo de ocio.

b) Las series de dibujos animadas que declaran ver, determinando la temática de sus series favoritas.

c) La consideración de los menores sobre si algunas de las aventuras animadas que veían podían darse en la realidad o no.

- $\mathrm{Y}$, a aquellos que se decantaron por una respuesta positiva, se les pidió que identificaran qué tipo de situaciones de ficción podían darse en la realidad.

\section{Datos de interés}

Si bien, las películas constituyen una opción de programación que ven habitualmente los menores encuestados en su tiempo de ocio y entretenimiento, además de los concursos televisivos, tal y como se refleja en la tabla 1. Sin embargo, son los dibujos animados los programas de TV más vistos por los niños y niñas de Educación Primaria. No obstante, debemos preguntarnos qué tipo de dibujos son los que consumen a diario, 
puesto que no todo formato animado, por el mero hecho de presentarse así, debe considerarse dirigido al público infantil y juvenil.

\begin{tabular}{|l|c|c|}
\hline $\begin{array}{c}\text { Tipo de programa que visionan los } \\
\text { menores encuestados }\end{array}$ & Niños (\%) & Niñas (\%) \\
\hline Dibujos animados & $\mathbf{3 4 , 8}$ & $\mathbf{3 2 , 9}$ \\
\hline Teleseries & 8 & 11,2 \\
\hline Películas & $\mathbf{2 2}$ & 19,8 \\
\hline Documentales & $\mathbf{1 4}$ & 10,8 \\
\hline Corazón & 1,6 & 1,4 \\
\hline Concursos & 13,2 & $\mathbf{1 3 , 7}$ \\
\hline Telenovelas & 3,3 & 9,2 \\
\hline Otros & 3,1 & 1 \\
\hline
\end{tabular}

Tabla1. Distribución porcentual de los diferentes tipos de programas televisivos que los menores encuestados manifiestan visionar en su tiempo de ocio

La preocupación por los contenidos y temáticas de los dibujos animados que ven los menores ha sido una constante en los últimos años (Del Moral, 1994; Valkenburg \& Janssen, 1999; Choma, Hossler y otros, 2004), sobre todo por el tipo de mensajes explícitos e implícitos que a menudo se encuentran en disonancia con los valores transmitidos en la escuela (Del Moral y Villalustre, 2006). De ahí que, en el cuestionario se incluyeran determinados ítems encaminados a identificar las series de dibujos animados preferidas por los menores encuestados.

\begin{tabular}{|l|c|c|}
\hline $\begin{array}{c}\text { Temáticas de los dibujos animados } \\
\text { que visionan los menores encuestados }\end{array}$ & Niños (\%) & Niñas (\%) \\
\hline Fantasía -Ficción & $\mathbf{1 8 , 2}$ & $\mathbf{2 8 , 2}$ \\
\hline Lucha & $\mathbf{2 3 , 6}$ & 7,7 \\
\hline Tema familiar & $\mathbf{3 5 , 1}$ & $\mathbf{4 2 , 2}$ \\
\hline Aventura & 9,4 & 12,9 \\
\hline Deportiva & 10,8 & 2,1 \\
\hline Romántica & 1,2 & 2,6 \\
\hline Educativa & 1,8 & 4,2 \\
\hline
\end{tabular}

Tabla 2. Distribución porcentual de las preferencias de los menores en cuanto a las temáticas de los dibujos animados que visionan con frecuencia

Los resultados son claros en cuanto a las series animadas preferidas por los menores encuestados, ya que seleccionan la temática familiar, englobando a series como Los Simpsons, Padre de Familia, etc., entre las que más les gustan, con una clara mayoría en porcentajes respecto a las demás opciones (el 35,1\% de los niños y algo más del 42\% 
de las niñas). Las series animadas de temática fantástica y ficción (con series como Kim Possible, La vida y obra de Juniper Lee, etc.), son las segundas seleccionadas por los escolares, según manifestaron un aproximado 18,2\% de los niños y un 28,2\% de las niñas.

Entre los motivos que señalan para justificar sus elecciones en cuanto a sus series de dibujos animados preferidas, la diversión y el entretenimiento son el principal motivo que les ha guiado a la hora de optar por las diferentes series animadas, tal y como manifestaron más del 62\% de los encuestados.

No obstante, algo más del $9 \%$ de los niños y un 3\% de las niñas consultadas manifestaron su preferencia por series de dibujos animados que poseían contenidos violentos. Aunque dichos porcentajes no sean alarmistas, si puede llegar a ser preocupante que los menores justifiquen sus preferencias por el contenido violento que éstas contengan.

Preguntados los menores por su consideración sobre si algunas de las situaciones representadas en las series de dibujos animados, -que habitualmente ven-, podían darse en la realidad, constatamos que más del 30\% de los niños y el $47 \%$ de las niñas afirman que sí.

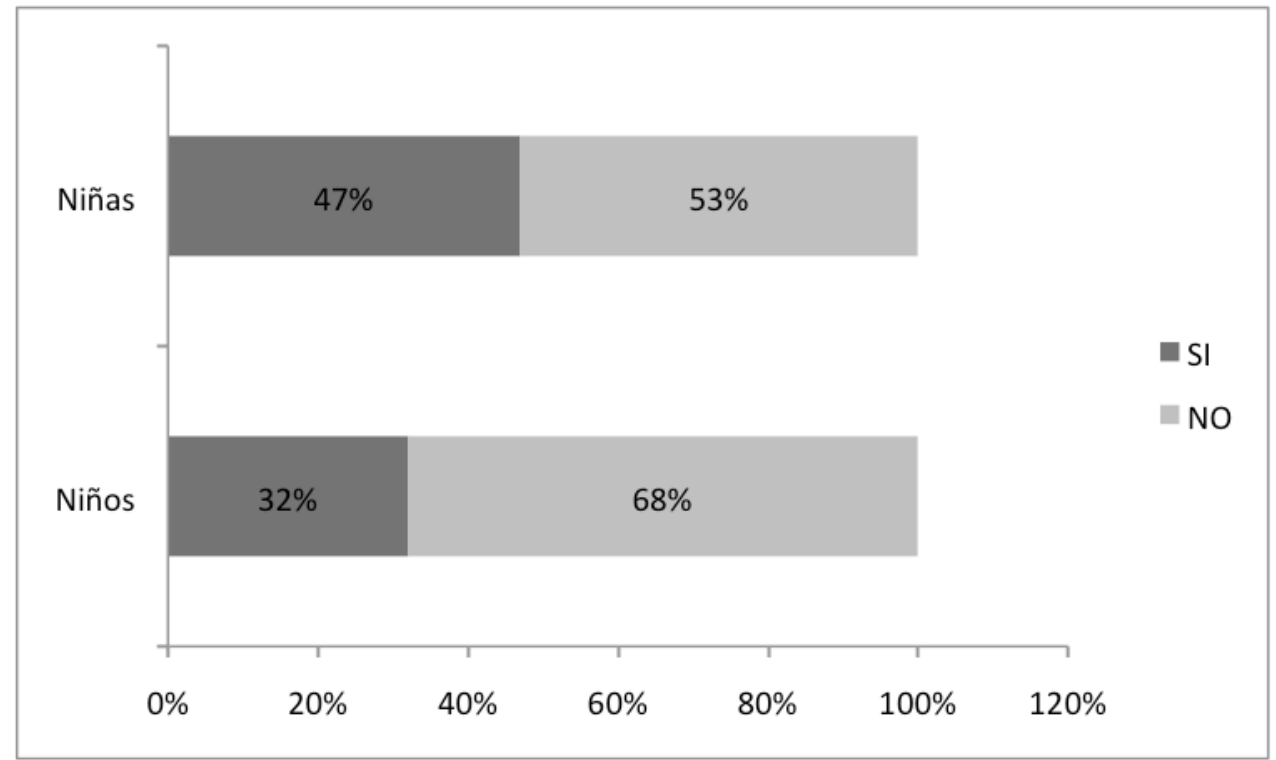

Gráfico 1. Distribución porcentual de las consideraciones de los menores en cuanto a si existen o no situaciones de ficción representadas en los dibujos animados que pueden darse en la realidad. 
Como se puede observar, más del 35\% de los niños y niñas establecen que las situaciones violentas de ficción representadas en los dibujos animados que ven con cierta frecuencia son un reflejo de situaciones que, consideran, pueden darse en la vida real.

\begin{tabular}{|l|c|c|}
\hline $\begin{array}{c}\text { Tipo situaciones ficticias que los } \\
\text { menores consideran que pueden } \\
\text { darse en la realidad }\end{array}$ & Niños (\%) & Niñas (\%) \\
\hline Violentas & $\mathbf{3 5 , 3}$ & $\mathbf{3 5 , 6}$ \\
\hline Ocio y diversión & 6,2 & 6,7 \\
\hline Fantásticas & $\mathbf{3 5 , 3}$ & $\mathbf{3 1}$ \\
\hline Deportivas & 12 & 3,8 \\
\hline Situaciones cotidianas & $\mathbf{3 3}$ & $\mathbf{4 2 , 2}$ \\
\hline
\end{tabular}

Tabla 3. Distribución porcentual del tipo de situaciones ficticias representadas en los dibujos animados que los menores consideran que pueden darse en un contexto real.

De los estudios llevados a cabo por Wright, Huston y otros (1994) se extrajo como elemento concluyente que los niños/as consideran que las situaciones que contemplan en la televisión, -incluidas las series de animación-, que parecen reales, las perciben como tales.

Por ello, y a partir de los datos aquí mostrados, en los que se evidencia como los escolares visionan todo tipo de manifestaciones violentas, fantásticas, etc. tanto en los dibujos animados como en las películas que dicen ver, sólo cabe reclamar una mayor coherencia a los responsables de la programación infantil, para velar por el tipo de contenidos que se exhiben, tal como recomiendan los estudios de Carter y Weaver (2003) al analizar los efectos de la violencia representada, -en los distintos medios de comunicación-, en la conducta de los espectadores.

Si tenemos en cuenta que el aprendizaje infantil se realiza según los postulados de la teoría del modelaje social de Bandura (1986), principalmente a través de la imitación, y son a menudo, los modelos televisivos mostrados en la pantalla los que se constituyen en referentes socio-morales para los más pequeños, aunque no siempre respondan a planteamientos educativos como sucede en algunos de los capítulos de las series animadas, como en el caso de la que un padre agrede a su hijo físicamente (Los Simpsons) o, en otro, se maltrata psicológicamente a su hija (Padre de Familia)..., no podemos más que mostrar nuestra preocupación, más aún, cuando los niños parecen 
haber asimilado la violencia como un componente más del contexto real en el que se desenvuelven, banalizando su verdadero sentido.

Si continuamos analizando los datos, observamos que más 35\% de los niños y, con porcentajes similares, el 31\% de las niñas consideran que las situaciones fantásticas que se exhiben en gran parte de las series animadas que consumen con cierta asiduidad pueden darse en la realidad, tales como Mirmo, el cual posee poderes para luchar contra el mal; o los superhéroes encarnados en las figuras de Superman, Spiderman, Batman, etc. Para Lavallée y Lebel (2007) los niños/as utilizan los programas de ficción como representaciones de la vida real para aprender del mundo en el que se desarrollan. Por tanto, los modelos que estos personajes fantásticos transmitan son de gran importancia, por la influencia psicológica y cognitiva que pueden ejercer entre los más pequeños.

La disociación entre ficción y realidad no deja de ser preocupante, pues la asimilación de estos modelos se constituyen en organizadores de la realidad, que pueden condicionar pautas de comportamiento y conductas.

Por otro lado, la representación de situaciones o escenas cotidianas que aparecen en las series de dibujos animados, según reconoce el 33\% de los niños, y algo más del $42 \%$ de las niñas consultadas, no dejan de ser ocasiones que pueden ser beneficiosas para afianzar aprendizajes, normas y valores, siempre y cuando éstas no limiten a una mera representación de estereotipos reduccionistas y, en ocasiones, discriminatorios, que sesguen y/o distorsionen la realidad.

\section{Claves para favorecer la distinción entre ficción-realidad y la adquisición de competencias mediáticas}

Hay que tener en cuenta la frágil línea que separa los límites entre el mundo real y el ficticio para los más pequeños, por lo que consideramos necesario y pertinente elaborar un conjunto de recomendaciones, tanto desde un punto de visto educativo y familiar como desde el ámbito de los medios de comunicación, para favorecer la adquisición y desarrollo de las competencias mediáticas que propicie que los niños/as puedan comprender que las situaciones ficticias no tienen que producirse necesariamente en un contexto real.

a. Desde el ámbito escolar y familiar: 
- Por un lado, es necesario establecer planes de formación integral del profesorado desde las administraciones educativas, orientados a ofrecer pautas para la integración de los medios de comunicación en las aulas, así como estrategias de análisis y estudio de los mismos como requisito previo a su integración curricular.

- La educación en competencias mediáticas, basadas en la adquisición de habilidades para aprender y enseñar a ver la televisión (Aguaded, 2005) mediante su integración curricular, posibilita el afianzamiento de operaciones formales orientadas a analizar críticamente los mensajes transmitidos en los medios de comunicación.

- La escuela puede ofrecer a los más pequeños los instrumentos cognitivos necesarios para marcar una línea divisoria entre ficción y realidad, mediante la transmisión paulatina y progresiva de un sistema racional y científico que dé respuesta a las situaciones confusas que en ocasiones se representan en las series de dibujos animados, sin necesidad de recurrir a un pensamiento mágico para su explicación.

- Por otro lado, la implicación de las familias en la educación de las competencias mediáticas es un elemento clave, pues ellas son los principales modelos y referentes a imitar por los más pequeños. Ellos pueden, de manera directa, marcar una clara distinción entre lo real y lo ficticio que se representa en las series de dibujos animados que sus hijos consumen, mediante la aportación de explicaciones racionales a los hechos y situaciones fantásticas que en ellos se exhiben.

- Establecer, asimismo, un control sobre la programación televisiva que se emite en horario protegido para menores, de modo, para ofrecerles contenidos creados y diseñados específicamente para ellos, carentes de contravalores y estereotipos que pudieran dificultar su desarrollo madurativo, o condicionar su percepción del mundo en el que viven.

\section{b. Desde el ámbito de los medios de comunicación:}

- Las cadenas televisivas deben favorecer la participación activa de la audiencia infantil a través de sus programaciones, y no considerarles meros consumidores 
pasivos. Deberían potenciar aprendizajes básicos mediante producciones con un carácter lúdico.

- Fomentar valores democráticos como el respeto a la dignidad de la persona, la honestidad, el cuidado del medioambiente, la salud, la multiculturalidad, etc. (Del Moral y Villalustre, 2010a), a través de las producciones audiovisuales, y más específicamente, de las series de dibujos animados.

- Ofrecer una programación infantil rica y variada, orientada a fomentar la adquisición de valores y afianzar ciertos aprendizajes, evitando posibles manipulaciones debido al desconocimiento del lenguaje específico que emplean los medios.

- Teniendo en cuenta que los más pequeños asumen lo representado en las series de dibujos animados de formal literal, es fundamental que los mensajes transmitidos sean claros y directos evitando sesgos o múltiples interpretaciones que confundan a los niños/as. Intentando, establecer una clara división entre las situaciones que pueden darse en un mundo real y las dadas en el ficticio.

\section{A modo de conclusión}

A tenor de los datos presentados, la realidad exige que desde la escuela se pongan en marcha programas educativos que favorezcan el desarrollo de determinadas competencias, encaminadas a que los niños y niñas aprendan a elegir y a disfrutar de los diferentes programas televisivos que tienen a su alcance. Además, de facilitarles estrategias para que sean capaces de leer e interpretar críticamente los mensajes que éstos transmiten, que les lleven a un consumo exigente no conformista con productos mediocres que empobrecen su actividad cognitiva, o la reducen a meras ejecuciones irreflexivas (Del Moral y Villalustre, 2010b).

No podemos dejar de manifestar nuestra preocupación ante la falta de unos referentes televisivos óptimos que secunden los objetivos educativos que se propugnan desde la escuela, de ahí que aplaudamos iniciativas institucionales llevadas a cabo en otros países, como la descrita por Anderson (2003), orientadas a velar por los contenidos que se exhiben públicamente en las televisiones financiadas con fondos públicos, y que repercuten directamente en el desarrollo psico-afectivo de los menores. 
De igual modo, la educación basada en un discurso racional y científico, en el que intervengan conjuntamente las familias, los docentes y los educadores, en general, debe proporcionar los instrumentos y estrategias necesarias para que el niño/a decodifique los mensajes fantásticos e irreales que se transmiten en diferentes series de dibujos animados, de tal modo, que sea capaz de establecer una clara línea divisoria entre aquellos componentes de las historias narradas que sean ficticios y aquellos que puedan considerase como próximos a una realidad cercana.

\section{Referencias}

ANDERSON, D.R. (2003): The Children's Television Act: A public policy that benefits children. Journal of Applied Developmental Psychology, Vol. 24, $\mathrm{n}^{0}$ 3, August 2003; 337-340.

AGUADED, I. (2005). Enseñar a ver la televisión: una apuesta necesaria y posible. Comunicar, 25; 51-55.

BANDURA, A. (1983). Principios de Modificación de Conducta. Editorial Sígueme. Salamanca.

BANDURA, A. (1986). Social foundations of thought and action: A social cognitive theory. Englewood Cliffs, NJ: Prentice-Hall.

CARTER, C. \& WEAVER, C.K. (2003). Violence and the Media. Philadelphia: Open University Press.

CHOMA, C.J.; HOSSLER, S.; LEU, R.; NELSON D.; RAY, S.; WILCOX, B.; YBARRA, B. (2004). Effects of Cartoons on Children. Accesible online en http://www.bgsu.edu/departments/tcom/faculty/ha/tcom103fall2004/gp9/ [consultado agosto 2008].

DEL MORAL, M.E. (1994). Influencias psico-socioeduativas de los dibujos animados en los niños/as de primaria. Tesis doctoral. Madrid: UNED. 
DEL MORAL, M.E. (2004). Modelos familiares en crisis: El hiperrealismo de las series animadas de Shin Chan, Padre de familia y Los Simpson. Comunicación y Pedagogía: Nuevas Tecnologías y Recursos Didácticos, 197; 55-59.

DEL MORAL, M.E. (2010). Fines de los medios de comunicación y niveles de intervención. La audiencia infantil. En Del Moral, M.E. (coord.). Televisión: desarrollo de la creatividad e infancia. Barcelona: Editorial Octaedro; 21-30.

DEL MORAL, M.E. \& VILLALUSTRE, L. (2006). Valores televisivos versus valores educativos: modelos cuestionables para el aprendizaje social. Comunicación y pedagogía: Nuevas tecnologías y recursos didácticos, 214; 35-40.

DEL MORAL, M.E. \& VILLALUSTRE, L. (2008). Televisión y videojuegos: apuntes sobre el consumo de los escolares asturianos. Comunicación y Pedagogía: Nuevas Tecnologías y Recursos Didácticos, 231-232; 20-26.

DEL MORAL, M.E. \& VILLALUSTRE, L. (2010a). Consumo televisivo y de videojuegos de los escolares asturianos versus desarrollo de competencias audiovisuales y digitales. En Del Moral, M.E. (coord.). Televisión: desarrollo de la creatividad e infancia. Barcelona: Editorial Octaedro; 31-46.

DEL MORAL, M.E. \& VILLALUSTRE, L. (2010b). Experiencias creativas de televisión infantil en el ámbito internacional. En Del Moral, M.E. (coord.). Televisión: desarrollo de la creatividad e infancia. Barcelona: Editorial Octaedro; 117-128.

GIMÉNEZ, M. (2003). ¿Existen las hadas y los monstruos? La distinción infantil entre lo real y lo mágico. Una revisión de la literatura. Estudios de Psicología, 24(3); 337352.

GORDO, J. (1999). Televisión, sueños y angustia en los niños. Comunicar, 12; 198203. 
HARRIS, P. \& OTROS (1991). Monsters, ghots and witches: Testing the limits of the fantasty-reality distinction in young children. British Journal of Developmental Psychology, 9; 105-123.

LAVALLÉE M. \& LEBEL, E. (2007). Distinción entre ficción y realidad en niños de 7 a 12 años por medio de fragmentos de diferentes tipos de programas de televisión. $I X$ Congreso de Investigación Educativa. 5-9 noviembre. México.

PIAGET, J. (1933). La representación del mundo en el niño. Madrid: Morata.

SUBBOTSKY, E. (2000). Phenomenalistic perception and rational understanding in the mind of an individual: a fight for dominance. In Rosengren, C. \& otros (eds.). Imagining the impossible. Magic, scientific and realigious thinking in children. Cambridge: Cambridge University Press; 35-74.

TAYLOR, M. (1999). Imaginary companions and the children who create them. Oxford: Oxford University Press.

VALKENBURG, P.M. \& JANSSEN, S.C. (1999). What do children value in entertainment programs? A cross-cultural investigation. The Journal of Communication, 49 (2); 3-21.

WRIGHT, J. C., HUSTON, A.C., \& Otros. (1994). Young children's perceptions of television reality: Determinants and developmental differences. Developmental Psychology, 30; 229-239.

WOOLLEY, J. \& PHEPLS, K. (1994). Young children's practical reasoning about imagination. British Journal of Developmental Psychology, 12; 53-67. 